Bentham open
CrossMark
Content list available at: www.benthamopen.com/TOCIEJ/
DOI: $10.2174 / 1874149501610010125$

\title{
Slope Stability Analysis Under Combined Failure Criteria
}

\author{
Kai $\mathrm{Su}^{1}$, Yin $\mathrm{Li}^{2, *}$ and Dan Cheng ${ }^{1}$ \\ ${ }^{I}$ State Key Laboratory of Water Resources and Hydropower Engineering Science, Wuhan University, Wuhan, 430072, \\ P. R. China \\ ${ }^{2}$ Earthquake Administration of Hubei Province, Wuhan, 430070, P. R. China
}

\begin{abstract}
Strength reduction finite element method (SRFEM) has been widely used to analyze the slope stability. Strength Reduction Factor (SRF) is yielded as the slope Factor Of Safety (FOS) when a running-though shear failure zone comes into being, in which the Plastic Element EQuivalent strain (PEEQ) is employed as the judgment of shear failure initiation in this paper. Moreover, the filed variable is set as same as SRF along the solution processing, FOS can be directly determined as the corresponding value of field variable when the shear failure zone goes through. Three typical slopes with varying foot gradients of 26.6, 45 and 78.7 in degree are analyzed and fantastic results have been yielded, well agreeing with the Spencer's results, when the linear Mohr-coulomb failure criterion is employed. However, during the solution process, tensile failure zone initiates at the slope top while the plastic failure zone initiates at the slope toe and this indicates that the failure mode of slope is combined. The results show that the combined failure zone with plastic failure and tensile failure appears much earlier than the unique plastic failure zone, which indicates that the traditional analytic method and SRFEM based on the unique linear Mohr-coulomb plasticity criteria overestimated the slope stability factor.
\end{abstract}

Keywords: Combined failure criteria, safety factor, slope stability, strength reduction factor, strength reduction finite element method.

\section{INTRODUCTION}

Limit equilibrium methods are widely employed to analyze slope stability with the simple computation, which have a long history and abundant using experience. And a comprehensive survey of equilibrium methods is presented by Duncan [1], including Method of Slices, Bishop's Modified Method, Price's Method, Spencer's Method and so on. The most difficulty with all the equilibrium method is that they are based on the assumptions that the failing soil mass can be divided into slices, with consequent implications for equilibrium. As finite element method (FEM) can meet static equilibrium equation and strain compatibility, it represents an alternative approach for slope stability analysis without assuming the shape or location of the failure surface and slice side forces and it has become very popular for evaluating slope stability in which the linear Mohr-Coulomb failure criterion was often used [1 - 6]. However, the experimental results show that the strength envelopes of almost all geo-materials are characteristically nonlinear [7 - 12] and that the linear failure criterion is a special case of nonlinear failure criteria. And most of these nonlinear failure methods are relative complicated procedure, walking farer way from the simple computation [8, 12 - 15]. In our paper a simple combined failure criterion with linear Mohr-Coulomb failure criterion and maximum principal tensile stress criterion are employed to determine the slope failure upon the shear failure zone and tensile failure zone.

\section{BASIC THEORY AND DEFINITION}

\subsection{Strength Reduction Finite Element Method}

The Factor of Safety $(F O S)$ of the slope is defined here as the factor by which the original shear strength parameters

\footnotetext{
* Address correspondence to this author at the Earthquake Administration of Hubei Province, Wuhan, 430070, P. R. China; Tel: (+86)027-65390353; Fax: (+86)027-65390367; E-mail: yubai1979@163.com
} 
must be divided in order to bring the slope to the failure $[2-4,16]$. And the factored shear strength parameters $C^{\prime}$ and $\varphi^{\prime}$ are defined as follows, respectively.

$$
\begin{gathered}
C^{\prime}=C / S R F \\
\varphi^{\prime}=\arctan (\tan \varphi / S R F)
\end{gathered}
$$

Where $S R F$ is "Strength Reduction Factor", $\varphi$ is the original friction angle (in degree), $C$ is the original cohesion. To find the exact Factor of Safety $(F O S)$, it is necessary to initiate a systematic search for the $S R F$ value that will just cause the slope failure, and FOS is determined as the corresponding $S R F$ value, $F O S=S R F$.

\subsection{Slope Failure Definition}

There are several popular definitions of failures, such as some tests of bulging of the slope profile; limiting of the shear stresses on the potential failure surface and non-convergence of the solution. When the solution cannot converge with a user-specified maximum number of iterations, this implication is that no stress distribution can be found to match both the failure criterion and global equilibrium [3]. And most solution chose an iteration ceiling of 1000, which most depends on the user's experience and brings quite high requirement for geology and civil engineers. Before nonconvergence of the solution appearance, there will be a running-through zone of plastic strain along a sliding surface from slope toe to the top [17], which can be easily found beyond primary operation experience of common commercial software. This running-through moment is assumed as the slope failure time and FOS is achieved as the corresponding $S R F$ at this moment in this paper.

\subsection{Mohr-Coulomb Plastic Criterion}

The Mohr-Coulomb criterion assumes that yield occurs when the shear stress on any point in a material reaches a value that depends linearly on the normal stress in the same plane (Fig. 1). The yield line is the best straight line that touches these Mohr's circles [18].

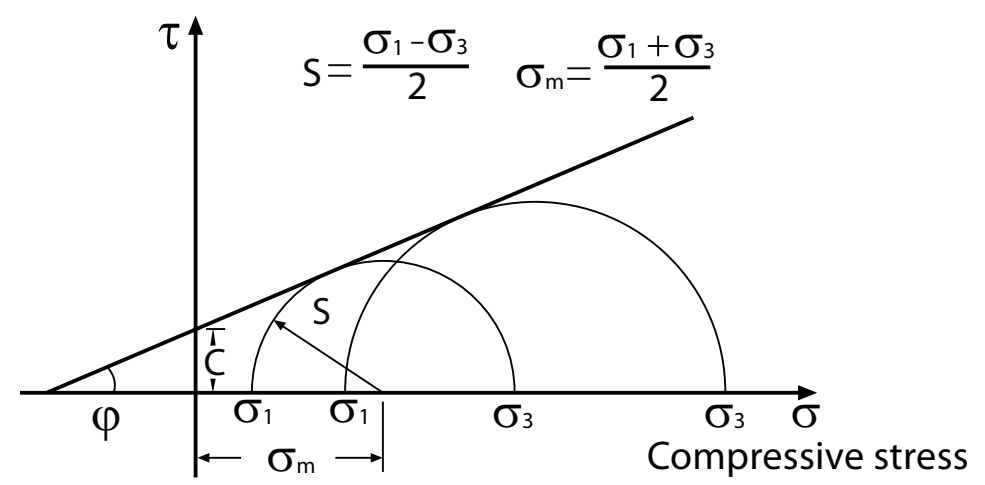

Fig. (1). Linear Mohr-Coulomb failure criterion.

Therefore, the Mohr-Coulomb model is defined by

$$
\tau=c-\sigma \cdot \tan \varphi
$$

Where $\sigma$ is positive in compression. From Mohr's circle,

$$
\begin{gathered}
\tau=s \cdot \cos \varphi \\
\sigma=\sigma_{m}+s \cdot \sin \varphi
\end{gathered}
$$

Substituting for $\tau$ and $\sigma$, multiplying both sides by $\cos \varphi$, and reducing, the Mohr-Coulomb model can be written as

$$
s+\sigma_{m} \sin \varphi-c \cos \varphi=0
$$


Where $S$ is half of the difference between the maximum principal stress, $\sigma_{1}$, and the minimum principal stress, $\sigma_{3}$,

$$
s=\frac{1}{2}\left(\sigma_{1}-\sigma_{3}\right)
$$

$\sigma_{m}$ is the average of the maximum and minimum principal stresses,

$$
\sigma_{m}=\frac{1}{2}\left(\sigma_{1}+\sigma_{3}\right)
$$

and $\varphi$ is the friction angle.

\subsection{Geometric and Material Parameters}

Three typical slopes are employed in this paper (geometric parameters are listed in Table 1) while the material properties, including unit weight, deformation modulus, Poisson's ratio and original shear strength parameters $C$ (Cohesion) and $\varphi$ (Friction angle), are presented in Table 2. And a value of the dilation angle, $\psi=0$, is used in this paper, corresponding to a non-associated flow rule with zero volume change during yield. Maximum element length, $L$, is set as one sixtieth of slope height, $H$.

\begin{tabular}{|c|c|c|c|c|c|c|c|}
\hline Model & $\mathbf{H}, \mathrm{m}$ & $\mathrm{AH} / \mathrm{H}$ & TH/H & DH/H & $\mathrm{BH} / \mathrm{H}$ & Foot gradient $\alpha,{ }^{\circ}$ & TH \\
\hline M1 & 10 & 2.00 & 2.00 & 2.00 & 6.00 & 26.6 & 陆 \\
\hline M2 & 20 & 1.5 & 2.75 & 2.00 & 5.25 & 45.0 & 树 \\
\hline M3 & 100 & 1.00 & 1.00 & 1.7 & 2.2 & 78.7 & H. BH \\
\hline
\end{tabular}

Table 1. Geometric parameters.

Table 2. Material properties.

\begin{tabular}{|c|c|c|c|c|c|}
\hline Model & Unit weight, $\mathbf{M N} / \mathbf{m}^{\mathbf{3}}$ & Deformation modulus, GPa & Poisson's ratio & Cohesion, Kpa & Friction angle, ${ }^{\circ}$ \\
\hline M1 & 0.020 & 0.1 & 0.3 & 15 & 20 \\
\hline M2 & 0.020 & 0.1 & 0.3 & 42 & 17 \\
\hline M3 & 0.020 & 10 & 0.28 & 400 & 23 \\
\hline
\end{tabular}

\section{SLOPE STABILITY UNDER MOHR-COULOMB PLASTIC CRITERION}

The slope media shear strength parameters including cohesion $C$ and friction angle $\varphi$, vary with the system field variable during the solution process while the field variable is chosen as same as $S R F$. The field variable value increases from minimum value to maximum during the solution while the soil parameters, including cohesion $C$ and friction angle $\varphi$, are divided by the according field variable value. From Fig. (2), we can see that a running-through shear failure zone completed at $S R F=1.602,1.217$ and 1.263 for M1, M2 and M3, respectively, which agreed well with the Spencer's solution of $F O S=1.59$ (M1), 1.20 (M2) and 1.27 (M3). Moreover, the log spiral sliding surfaces could be determined upon the distribution of the displacement vectors and contours, as shown in Figs. (3 and 4).

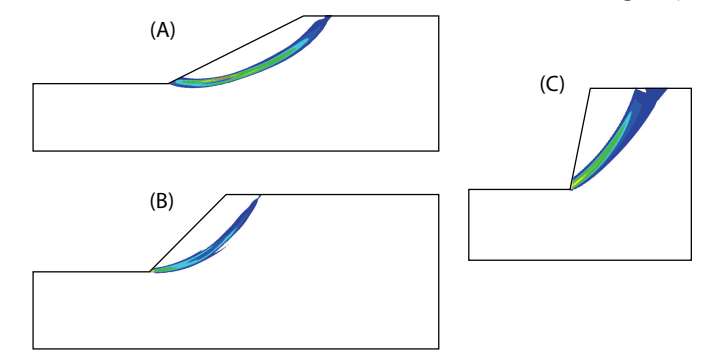

Fig. (2). Plastic failure zone determined by Plastic Element Equivalent strain (PEEQ). (A) M1, $S R F=1.602,(\mathbf{B}) \mathrm{M} 2, S R F=1.217,(\mathbf{C})$ $\mathrm{M} 3, S R F=1.263$. 


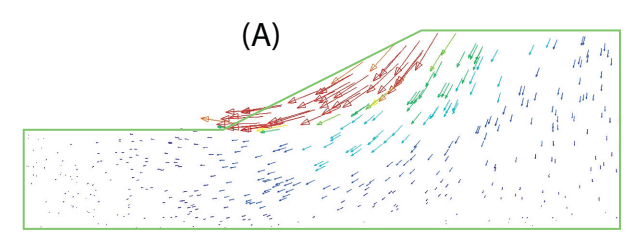

(B)

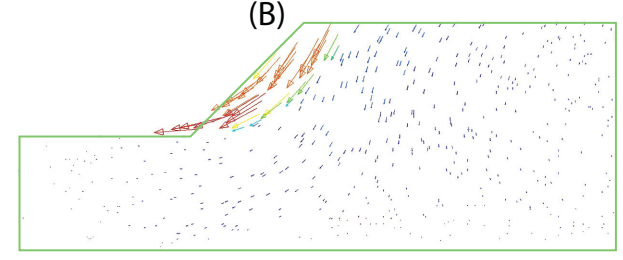

(C)

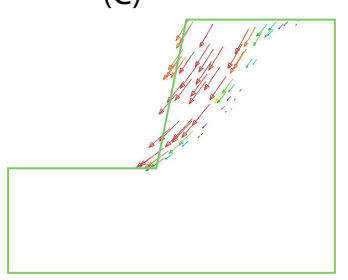

Fig. (3). Displacement vectors of nodes. (A) M1, $S R F=1.602$, (B) M2, $S R F=1.217$, (C) M3, $S R F=1.263$.
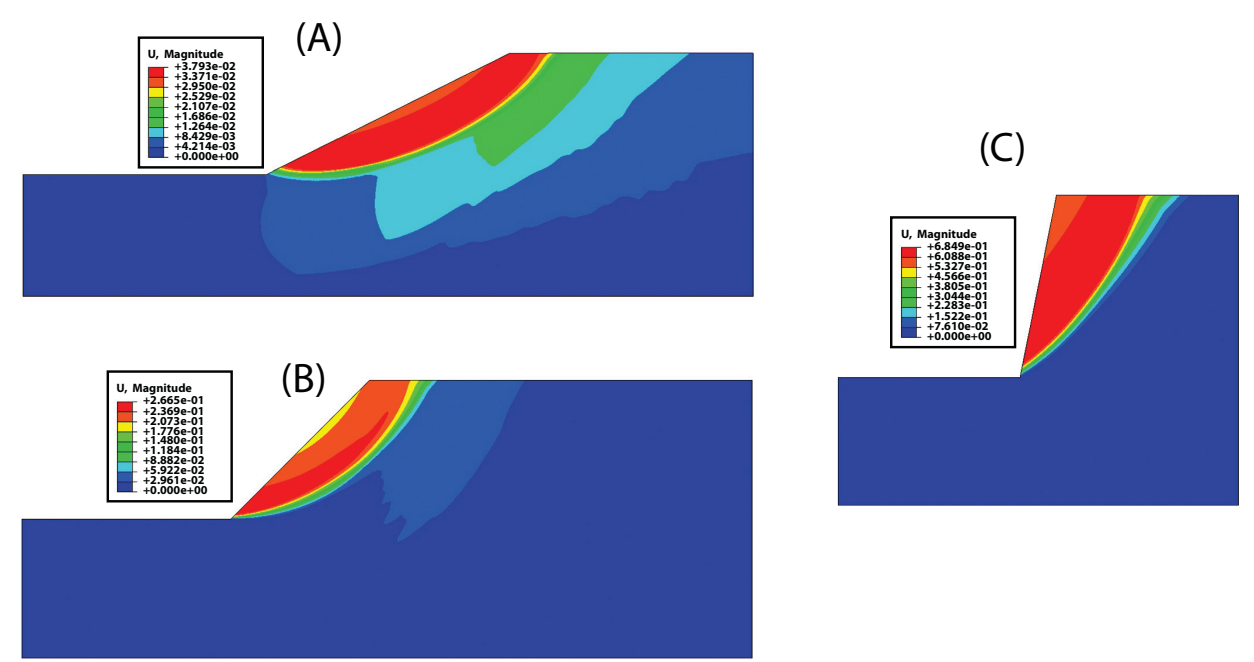

Fig. (4). Displacement contours to indicate the potential sliding surface. (A) M1, $S R F=1.602$, (B) M2, $S R F=1.217,(\mathbf{C}) \mathrm{M} 3$, $S R F=1.263$.

\section{SLOPE STABILITY UNDER COMBINED FAILURE CRITERION}

\subsection{Combined Failure Criterion}

Most experimental results show that the linear failure criterion is a special case of nonlinear failure criteria while the strength envelopes of almost all geo-materials are characteristically nonlinear. And most of these nonlinear failure methods are relativeby a complicated procedure, walking farer way from the simple computation, beyond most engineers' capacities and not suitable to wider application $[8,12,13]$. In our paper, a simple combined failure criterion with linear Mohr-Coulomb failure criterion and maximum principal tensile stress criterion are employed to determine the shear failure zone and tensile failure zone as follows (Eqn.7 \& Fig. 5).

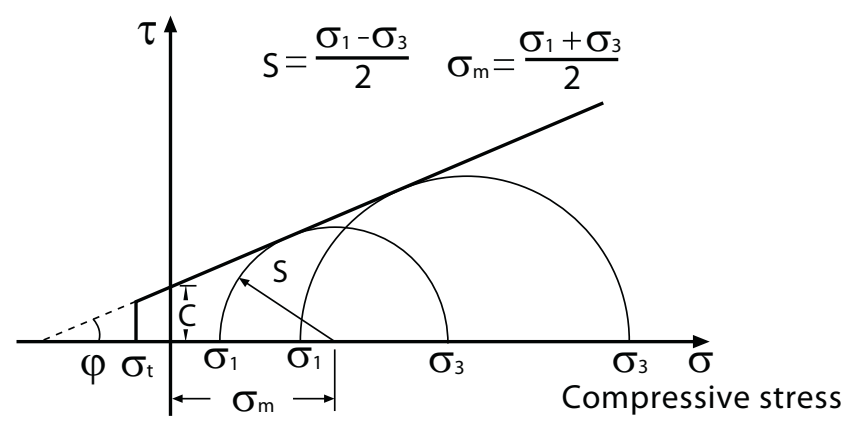

Fig. (5). Combined failure criterion by linear Mohr-Coulomb failure criterion and maximum principal tensile stress criterion. 


$$
\left\{\begin{array}{c}
\tau=c-\sigma \cdot \tan \varphi \\
\sigma_{1}=\sigma_{t}
\end{array}\right.
$$

Where $\sigma_{1}, \sigma_{t}$ are the maximum principal stress and tensile strength of slope media, respectively, and a value of $\sigma_{t}=0$ is used in this paper.

\subsection{Combined Failure Zone and FOS Determination}

During the solution progress, we can see that the tensile failure zone developed from the slope top while the shear failure zone developed from the slope toe, as shown in (Fig. 6). When the shear failure zone and tensile failure zone goes through each other, the slopes will lose the stability and receive the whole failure (Fig. 7).

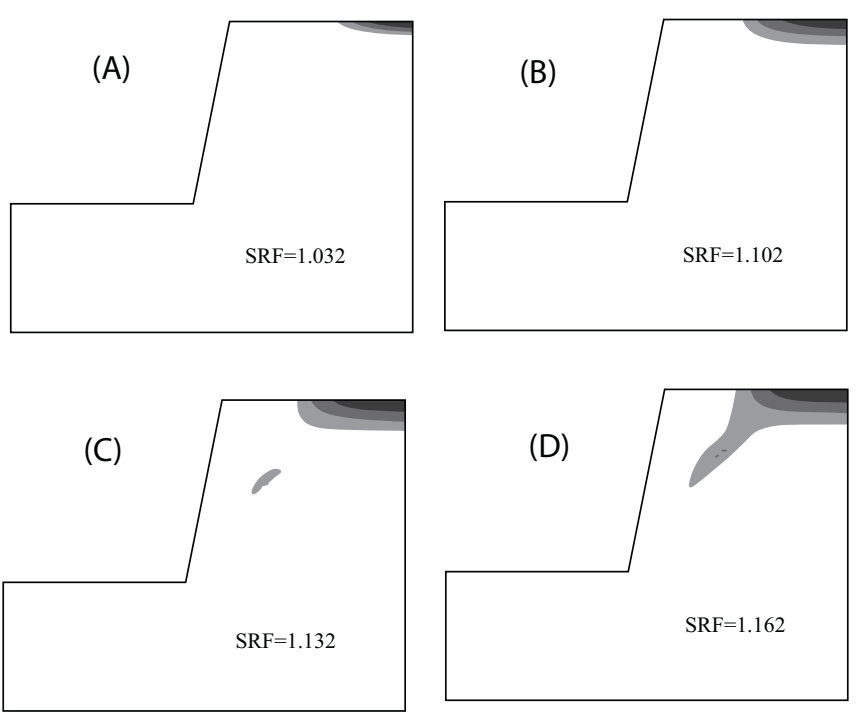

Fig. (6). Tensile failure zone initiation and propagation with increasing $S R F$. (M3, $\left.\sigma_{t}=0\right)$, (A) Tensile failure initiation from the right top near the boundary when $S R F=1.032$, (B) Tensile failure propagation towards slope inside from right top when $S R F=1.102,(\mathbf{C})$ Another tensile failure zone initiation in the slope deep element when $S R F=1.132$, (D) Deep failure zone and top-right failure zone going-through when $S R F=1.162$.

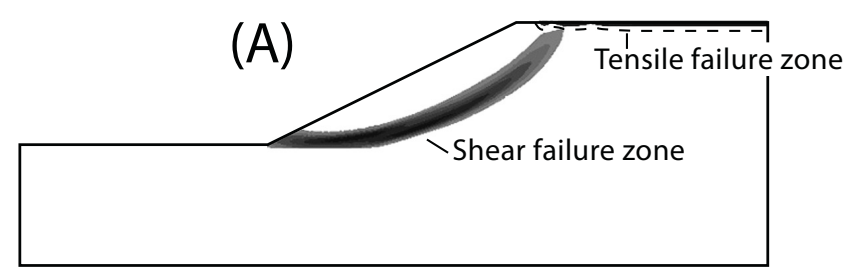

(B)

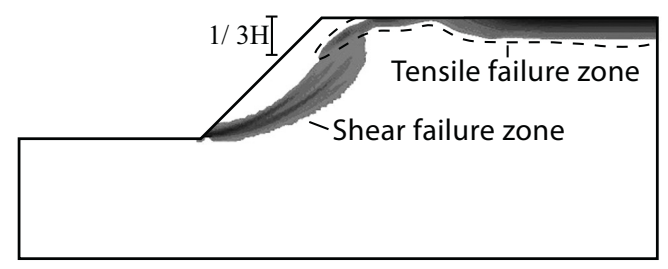

(C)

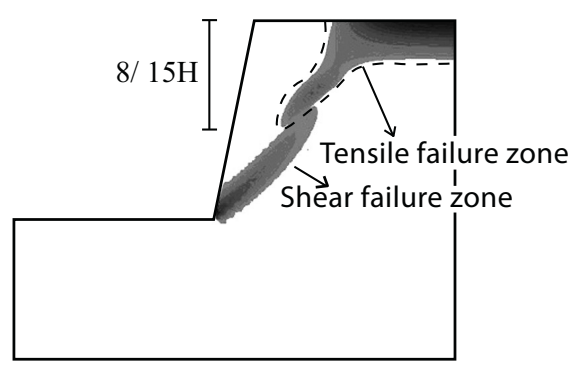

Fig. (7). Combined failure zone under combined criteria of shear failure and tensile failure. (A) M1, $S R F=1.592$, (B) M2, $S R F=1.202$, (C) M3, $S R F=1.162$.

Given the combined failure zone as the definition of the slope failure, we can find that FOS under combined failure criterion is 1.592(M1), 1.202(M2) and 1.162(M3), which are less than 1.602(M1), 1.217(M2) and 1.263(M3) under linear Mohr-Coulomb failure criterion, respectively. Furthermore, we can find that the foot gradient has dramatical 
influence on the tensile failure zone, and that the total height of failure zone, divided by slope height $\mathrm{H}$, developed from less than one tenth, one third time to eight fifths times when foot gradient increases from $26.6^{\circ}, 45.0^{\circ}$ to $78.7^{\circ}$.

\section{CONCLUSION}

The strength reduction finite element method conjunction with linear Mohr-Coulomb failure criterion has been shown to be a reliable method for slope stability analysis, which has achieved well-agreed results with the Spencer's solution. One main advantage of this approach, failure definition under plastic zone upon the plastic element equivalent strain distribution, is that the factor of safety emerges naturally during the solution without requirement of deep experience on numerical solution for engineers when a system field variable is employed.

During the shear failure zone propagation from the slope toe, tensile failure emerges from the slope top and the foot gradient has great influence on the tensile failure distribution. And a combined failure criterion with linear MohrCoulomb failure criterion and maximum principal tensile stress failure criterion is introduced to determine the safety factor of slope. The results show that the safety factors are over estimated when the tensile failure criterion is not considered.

\section{CONFLICT OF INTEREST}

The authors confirm that this article content has no conflict of interest.

\section{ACKNOWLEDGEMENTS}

The article is based on a study carried out by the authors at the State Key Laboratory of Water Resources and Hydropower Engineering Science of P. R. China. The authors are grateful to the National Natural Science Fund Council of P. R. China for its financial support (No. 51179140, No. 51579194) and acknowledge the support provided by the Open Project of Guangxi Key Laboratory of Disaster Prevention and Structural Safety of P. R. China (No. 2013ZDK07).

\section{REFERENCES}

[1] J.M. Duncan, "State of the art: Limit equilibrium and finite-element analysis of slopes", J. Geotech. Eng., vol. 122, no. 7, pp. 577-596, 1996. [http://dx.doi.org/10.1061/(ASCE)0733-9410(1996)122:7(577)]

[2] E.M. Dawson, W.H. Roth, and A. Drescher, "Slope stability analysis by strength reduction", Geotechnique, vol. 49, pp. 835-840, 1999. [http://dx.doi.org/10.1680/geot.1999.49.6.835]

[3] D.V. Griffiths, and P.A. Lane, "Slope stability analysis by finite elements", Geotechnique, vol. 49, pp. 387-403, 1999. [http://dx.doi.org/10.1680/geot.1999.49.3.387]

[4] K. Su, and Y. Li, "Discussion of SRFEM with mohr-coulomb plasticity model in slope stability analysis", In: Power and Energy Engineering Conference (APPEEC). Asia-Pacific: Shanghai, 2012, pp. 1-4. [http://dx.doi.org/10.1109/APPEEC.2012.6307001]

[5] O.C. Taylor, The Finite Element Method, $4^{\text {th }}$ ed. McGraw Hill: London, New York, 1989.

[6] K. Ugai, "A method of calculation of total safety factor of slope by elasto-plastic FEM", Soil Found., vol. 29, pp. 190-195, 1989. [http://dx.doi.org/10.3208/sandf1972.29.2_190]

[7] L.X. Zhang, and W.F. Chen, Limit Analysis in Soil Mechanics. Elsevier: Amsterdam, 1990.

[8] X.J. Zhang, and W.F. Chen, "Stability analysis of slopes with general nonlinear failure criterion", Int. J. Numer. Anal. Methods Geomech., vol. 11 , no. 1 , pp. $33-50,1987$.

[http://dx.doi.org/10.1002/nag.1610110104]

[9] E. Hoek, and J.W. Bray, "The Institution of Mining and Metallurgy", In: Rock Slope Engineering, $3^{\text {rd }}$ ed. London, 1981.

[10] M. Maksimovic, "Nonlinear failure envelope for soils", J. Geotech. Eng., vol. 115, pp. 581-586, 1989. [http://dx.doi.org/10.1061/(ASCE)0733-9410(1989)115:4(581)]

[11] R. Baker, "Nonlinear mohr envelopes based on triaxial data", J. Geotech. Geoenviron. Eng., vol. 130, no. 5, pp. 498-506, 2004. [http://dx.doi.org/10.1061/(ASCE)1090-0241(2004)130:5(498)]

[12] L. Zhao, F. Yang, Y. Zhang, H. Dan, and W. Liu, "Effects of shear strength reduction strategies on safety factor of homogeneous slope based on a general nonlinear failure criterion", Comput. Geotech., vol. 63, pp. 215-228, 2015. [http://dx.doi.org/10.1016/j.compgeo.2014.08.015]

[13] X.L. Yang, and J.H. Yin, "Slope stability analysis with nonlinear failure criterion", J. Eng. Mech., vol. 130, pp. 267-273, 2004. [http://dx.doi.org/10.1061/(ASCE)0733-9399(2004)130:3(267)] 
[14] F. Kang, J. Li, and Z. Ma, "An artificial bee colony algorithm for locating the critical slip surface in slope stability analysis", Eng. Optim., vol. 45, pp. 207-223, 2013. [http://dx.doi.org/10.1080/0305215X.2012.665451]

[15] F. Kang, S. Han, R. Salgado, and J. Li, "System probabilistic stability analysis of soil slopes using Gaussian process regression with Latin hypercube sampling", Comput. Geotech., vol. 63, pp. 13-25, 2015. [http://dx.doi.org/10.1016/j.compgeo.2014.08.010]

[16] K. Su, and Y. Li, "Discussion of extended drucker-prager yield criterion in slope stability analysis", In: Power and Energy Engineering Conference, APPEEC. IEEE: Asia-Pacific, Wuhan, 2009, pp. 1-4. [http://dx.doi.org/10.1109/APPEEC.2009.4918285]

[17] Z.Y. Shang-yi, "Study on slope failure criterion in strength reduction finite element method", Chin. J. Rock Soil Mech., vol. 26, pp. 332-336, 2005 .

[18] D. Hibbitt, B. Karlsson, and P. Sorensen, ABAQUS Analysis User's Manual. Providence, RI, 2004.

$\begin{array}{ll}\text { Received: May 04, } 2015 & \text { Revised: September 30, } 2015 \quad \text { Accepted: September 30, 2015 } \\ \text { C) Su et al:; Licensee Bentham Open. } & \end{array}$

(C) Su et al:; Licensee Bentham Open.

This is an open access article licensed under the terms of the Creative Commons Attribution-Non-Commercial 4.0 International Public License (CC BY-NC 4.0) (https://creativecommons.org/licenses/by-nc/4.0/legalcode), which permits unrestricted, non-commercial use, distribution and reproduction in any medium, provided the work is properly cited. 